Original Research Paper

\title{
Glassy Amorphous Metal Injection Molded Induced Morphological Defects
}

\author{
${ }^{1}$ Raffaella Aversa, ${ }^{1}$ Daniela Parcesepe, ${ }^{2}$ Relly Victoria V. Petrescu, \\ ${ }^{3}$ Guanying Chen, ${ }^{2}$ Florian Ion T. Petrescu, ${ }^{1}$ Francesco Tamburrino and ${ }^{1}$ Antonio Apicella \\ ${ }^{1}$ Advanced Material Lab, Department of Architecture and Industrial Design, \\ Second University of Naples, 81031 Aversa (CE) Italy \\ ${ }^{2}$ ARoTMM-IFToMM, Bucharest Polytechnic University, Bucharest, (CE) Romania \\ ${ }^{3}$ Harbin Institute of Technology and SUNY Buffalo, China
}

Article history

Received: $12-12-2016$

Revised: $18-12-2016$

Accepted: 27-12-2016

Corresponding Author:

Florian Ion T. Petrescu

ARoTMM-IFToMM, Bucharest

Polytechnic University,

Bucharest, (CE) Romania;

Vice President of IFToMM,

ARoTMM, Bucharest branch;

Director of "MSSMM"

Industrial and Mechanical

Design master of TMR

Department; Member of the

Board of the SRR (the

Romanian Society of Robotics

Bucharest branch). Member:

SRR, SIAR, FISITA, AGIR.

Email: scipub02@gmail.com

\begin{abstract}
Melt rheology in injection molded metastable supercooled liquid metal of $\mathrm{Zr}_{44}-\mathrm{Ti}_{11}-\mathrm{Cu}_{10}-\mathrm{Ni}_{10}-\mathrm{Be}_{25}$ alloy may induce selective crystallizations. High mobility $\mathrm{Be}, \mathrm{Cu}$ and $\mathrm{Ni}$ atoms have been observed to differently crystallize in bulk metal glassy supercooled liquids. Here, we analyze the result of morphological microscopic observation conduct on Bulk Metallic Glass (BMG) with composition of a commercial liquid metal alloy (LM001B). The injection molded plate has been supplied by "Liquid Metals Technologies Inc, Ca USA" and manufactured using an Engel injection molding machine operating at $1050-1100^{\circ} \mathrm{C}$; the observed sample then has been cut by water jet. FEI Scios Dual-Beam has carried out the microscopic observation. Particularly, through a cross section, we observe the presence of crystalline phases on the short-range order. We investigate the presence of short-range order clusters, their distribution and the effect that they could cause on the alloys' behaviors and properties.
\end{abstract}

Keywords: Bulk Glass Metals, Rheology, Chemorheological Model, Segregation, Cold Crystallization

\section{Introduction}

Bulk Metallic Glasses (BMGs), even called bulk amorphous alloys, are a category of advanced materials with a disordered atomic-scale structure. Their unique microstructure often imparts outstanding properties (Huang et al., 2016) to the manufacts.

Scientists and researchers in the last years have been studying Zr-based bulk materials for their superior Glass Forming Ability (GFA) and their mechanical properties. Their characteristics range from high mechanical strength, high fracture strength, superior elastic limit to good and precise deformability, good ductility, low coefficient of thermal expansion and excellent corrosion/wear resistance (Trachenko, 2008).

BMGs multicomponent alloys based on $\mathrm{Zr}$ have superior Glass Forming Ability (GFA) and they can be produced into parts with thickness larger than a few centimeters by conventional melting and casting techniques (Liu et al., 2002).

Among the other, the advantage of BMGs is the netshape as-cast form that provides reduced process cost and gives the possibility to manufacture several custom tools related to peculiar applications in a large range of industrial fields.

Sufficiently high critical cooling rates $\left(>103^{\circ} \mathrm{K} / \mathrm{s}\right)$ are necessary to manufacture these glasses from the molten alloys, a rapid solidification technique, in fact, may preserve the liquid amorphous microstructure (Huang et al., 2016; Petrescu et al., 2015; 2016; Jamaluddin et al., 2016, Bush, 2000).

The microstructure is the most important characteristic of BMGs compared to conventional metals; ordinary metals have a long-range order crystalline structure; a periodic lattice where patterns repeat themselves. The microstructure of BMGs, conversely, does not present long-range order, but a short range organization amorphous structure, which is peculiar of glass materials (ceramics, polymers and metal); (Aversa et al., 2015; 2016a; Petrescu et al., 2016).

Here, we analyze the result of morphological microscopic observation made by Ion and electron microscopy. 


\section{Materials and Procedures}

Differential Scanning Calorimetry using a DSC 822 Mettler Toledo run at a constant heating rate of $1 \mathrm{~K} / \mathrm{min}$ has been used for the preliminary calorimetric analysis of our BMG alloy (Fig. 1).

The sample studied in the present paper is a Bulk Metallic Glass with composition of $\mathrm{Zr}_{44} \mathrm{Ti}_{11} \mathrm{Cu}_{10} \mathrm{Ni}_{10} \mathrm{Be}_{25}$ (LM001B, Liquid Metals Technologies Inc, Ca USA) with a thickness of $3 \mathrm{~mm}$ and a dimension of $13 \mathrm{~mm}$ per side Fig. 2. The samples was cut from a plate manufactured using an Engel injection molding machine operating at 1050$1100^{\circ} \mathrm{C}$. The sample was chosen because presenting an evident surface defect generated by the injection molding process. All cuts and samples preparations were obtained from the plate by water jet cuttings. FEI Scios Dual-Beam has been used for the micro and nano-characterization of the injection molded metal glasses structure. Particularly, we investigate for surface defects and presence of crystalline phases through Ion beam cross sections.

Microscopic observation of the internal surface morphology and cross-sections at level of the surface defect were made by means of FEI Scios Dual Beam using a Focused Ion Beam (FIB) for cross-sectioning and Scanning Electron Microscopy (SEM) for morphological analysis. The instrument was equipped with a chemical composition analysis detector Energy Dispersive Spectrometry (EDS).

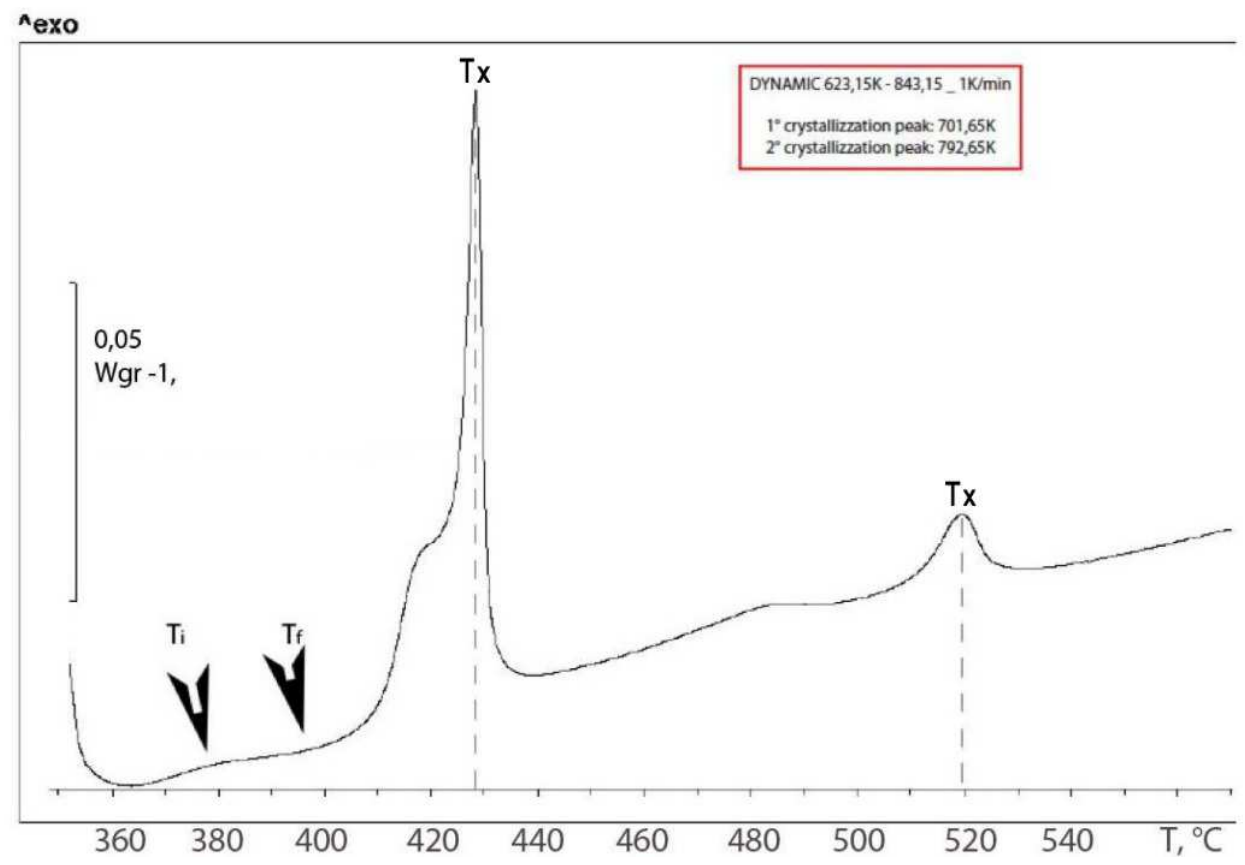

Fig. 1. DSC thermogram of $\mathrm{Zr}_{44}-\mathrm{Ti}_{11}-\mathrm{Cu} 10-\mathrm{Ni}_{10}-\mathrm{Be}_{25}$ metal glass Alloy: Heating rate $1^{\circ} \mathrm{K} / \mathrm{min}$

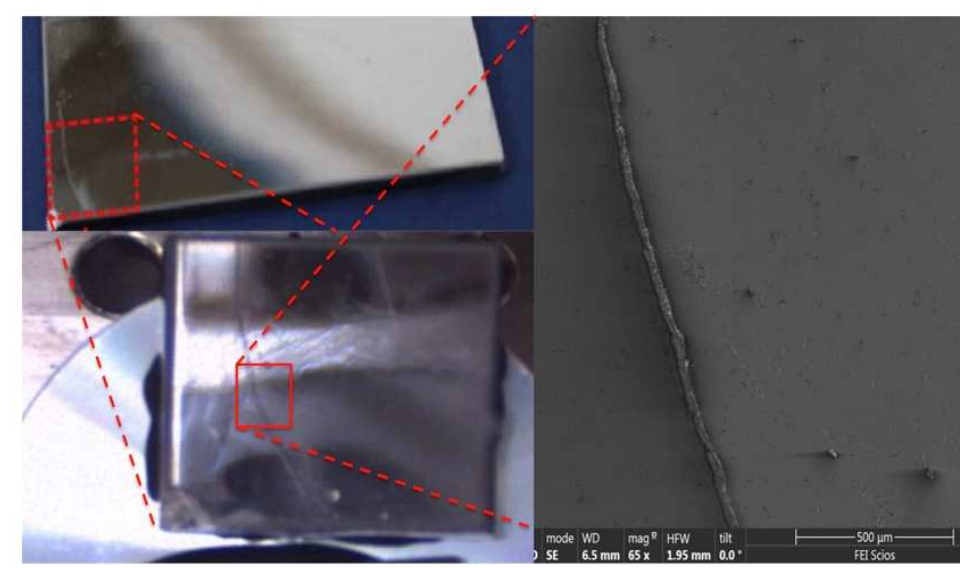

Fig. 2. Groove defect on the injection molded BMG slab analyzed using Dual Beam SE Microscopy 


\section{Results and Discussion}

The DSC thermogram is shows in Fig. 1 with a heating segment from 360 to $570^{\circ} \mathrm{C}$, showed glass transition at $380-395^{\circ} \mathrm{C}$ and four exothermic peaks of crystallization (Fig. 1), respectively at 418, 428, 482 and $520^{\circ} \mathrm{C}$ (Aversa and Apicella, 2016; Lewandowski et al., 2005; Geyer et al., 1996).

The first shoulder occurring at $418^{\circ} \mathrm{C}$, this behavior may be caused by the precipitation of icosahedral phase as an intermediate crystallization product (Murty and Hono, 2001), which, due to its higher mobility and small dimension, is probably a Be rich phase.

The second crystallization peak $\left(428^{\circ} \mathrm{C}\right)$ has been associated to $\mathrm{Cu}-\mathrm{Ni}$ rich phase (Aversa and Apicella, 2016).

The icosahedral phase formation has been depends on a significant atomic size mismatch between $\mathrm{Zr}, \mathrm{Cu}$ and $\mathrm{Ni}$ atoms that are significantly bigger than $\mathrm{Be}$ (Saida et al., 2000).

The surface SEM analysis showed a peculiar groove shape of the surface defect (jetting) that is characteristics of flow instability in injection molded parts (Fig. 3).

Similar surface defects in injection molding polymers are observed when the mold is to cold and/or the advancing front slow down leading to polymer vitrification or excessive high viscosity increase. In the case of glassy metal injection molding, the reason for surface defect may due to the same reasons: A too cold mold, in fact, could generate high temperature gradients in the molten plastic metal increasing the possibility of flow instability and groove and ripples formation.

The groove defect in Fig. 3 is filled with unknown materials. Figure 4 shows a portion of the defect where the debris has been removed.

The EDS chemical composition analysis of the material filling the ripple indicated that debris were composed by silicate and silico-alluminates from the water jet BMG plate cutting. Once removed, the morphology of the defect (Fig. 4) clearly indicates that the groove derives from melt flow instability.

The main aim of microscopic observation is to examine atoms arrangement and, in particular, the presence of short-range order clusters and their distribution (Pilarczyk and Podworny, 2015).

The use of Ion beam allows us to investigate on the internal morphology in the vicinity of the surface where the vitrification process first occurs.

A cross-section with a deepness of about $60 \mu \mathrm{m}$ was created using FIB. A Platinum deposition (Fig. 5a) was used as target for the Ion Beam, in order to sputter away matter when the beam hits the plate surface.

Figure 7 shows the details of the crystallized area, with indication of the points that have been analyzed for atomic composition. In particular, Fig. 6 shows crystalline-phase grains (black spot in Fig. 7) dispersed with some linear elements (white line in Fig. 7) in a glass phase matrix.

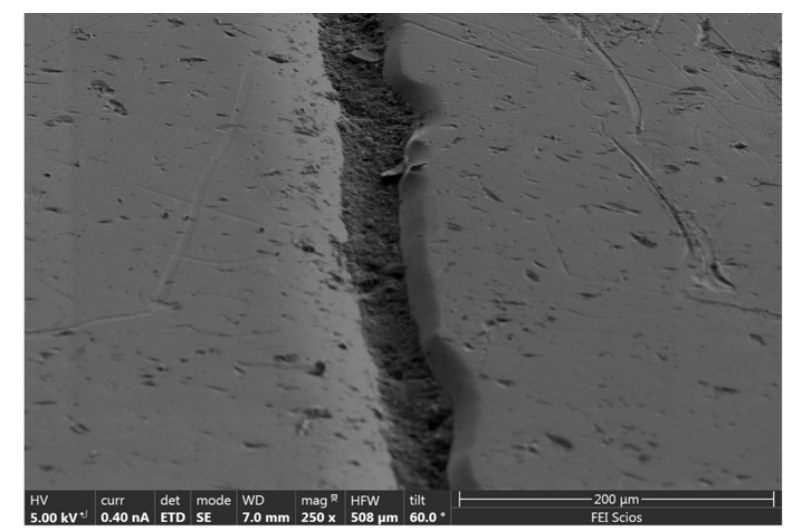

Fig. 3. Groove surface defect on the injection molded BMG slab analyzed using Dual Beam Microscopy

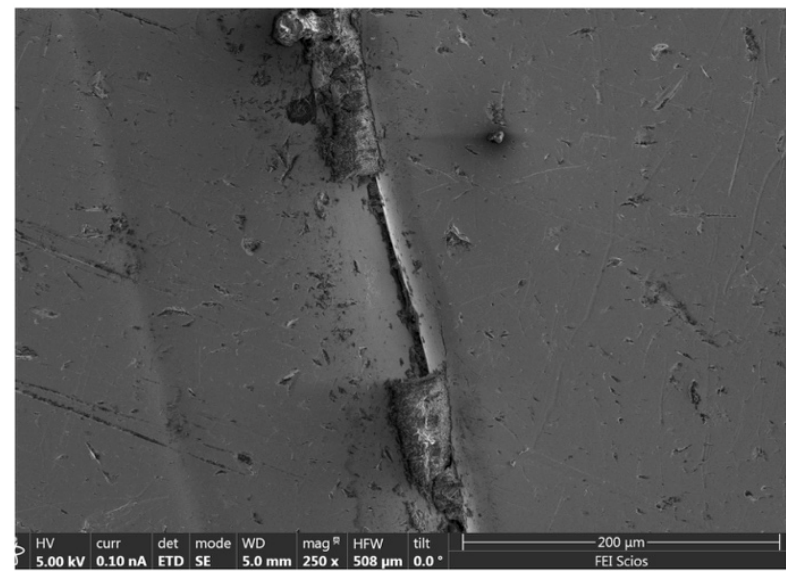

Fig. 4. Water jet debris removal in the surface groove defect of the injection molded BMG slab

Using EDS the chemical composition of chosen areas was analyzed.

The image of the sectioned front linear defect shows the presence of two types of crystalline inclusions: Namely, needle like (white in Fig. 7) and hexagonal crystals (upper right details of Fig. 7). The exact composition cannot be determined by EDS since very small atoms like Be are not detected. The EDS analysis has been performed on specific zones of the injection molded plate.

Crystalline inclusions have been described in literature; it has been reported by Liu et al. (2002) that the amount of crystalline inclusions decreases from the center to the external surface of a plate.

This decrease is supposedly due to cooling rate effects.

The cooling rate, in fact, is lower in the center than in the external areas of the sample and this condition increases the formation of a short-range order and therefore of crystalline-phase grains.

Moreover, in injection made parts, high shear stresses may be induced by the rheology of the molten alloy in the mold surface proximity where a region, neighboring the solidified glass, a still fluid but highly viscous layer exists (Fig. 8) (Morito and Egami, 1984). 


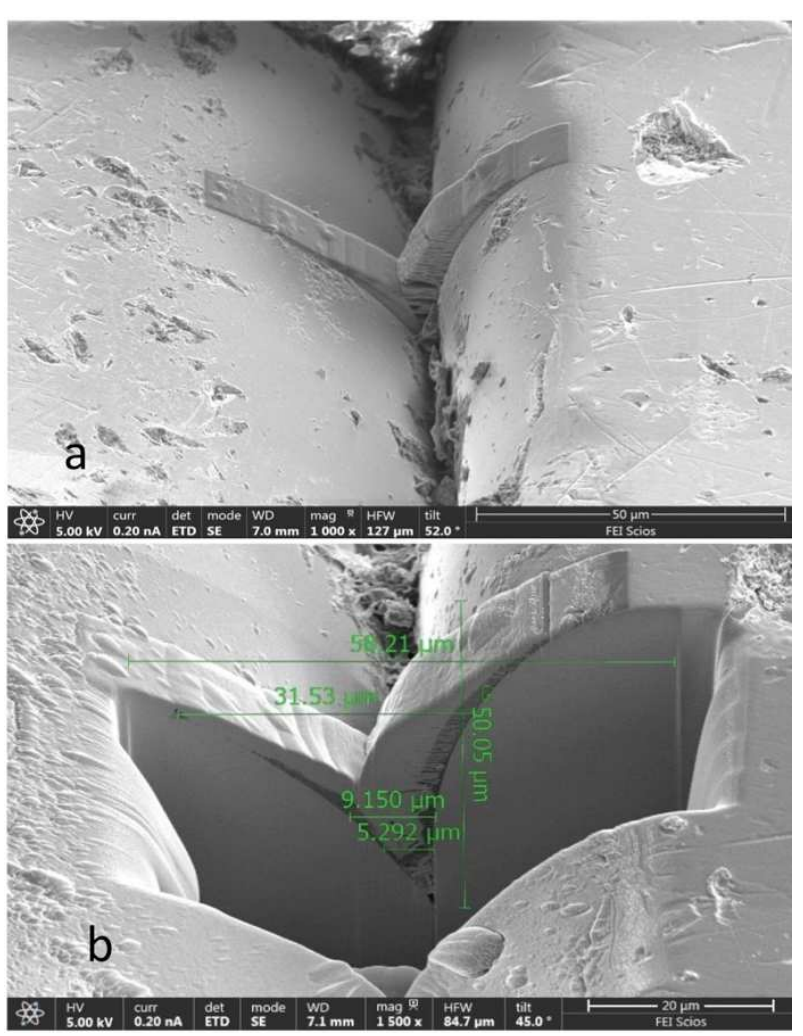

Fig. 5. Cross-section positioning and platinum deposition (a); morphological structure of the defect section (b)

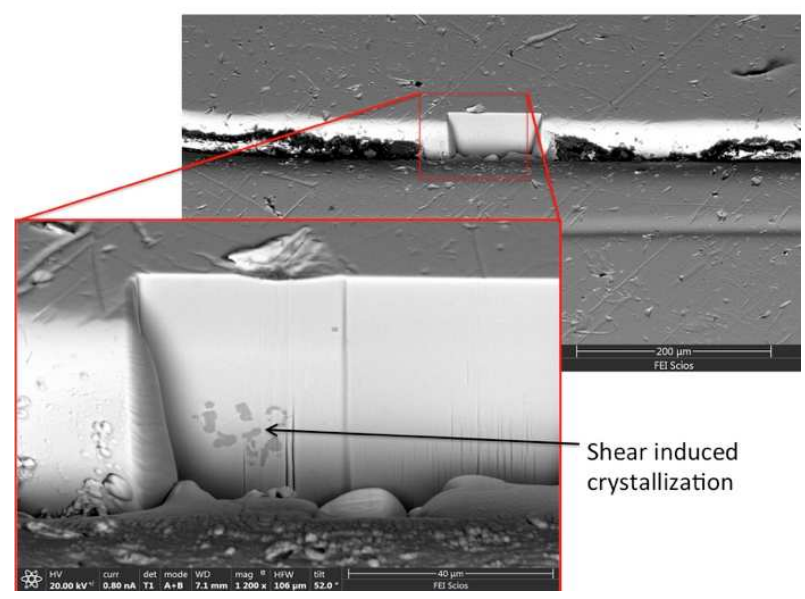

Fig. 6. Frontal view cross-section position in the groove. Detail of shear induced crystalline-phase grains

The EDS analysis has been then limited to the $\mathrm{Zr}$, Ti, $\mathrm{Cu}$ and $\mathrm{Ni}$ atoms. In particular, the analysis has been performed on the amorphous phase (either on the surface and internally in the vicinity of the surface) and on the two types of crystalline inclusions.

These areas are indicated in Figure 7 as S41, S42 and S43 (white needle like crystals), A44 and A46 (hexagonal dark crystals) and A45 (amorphous glassy metal).

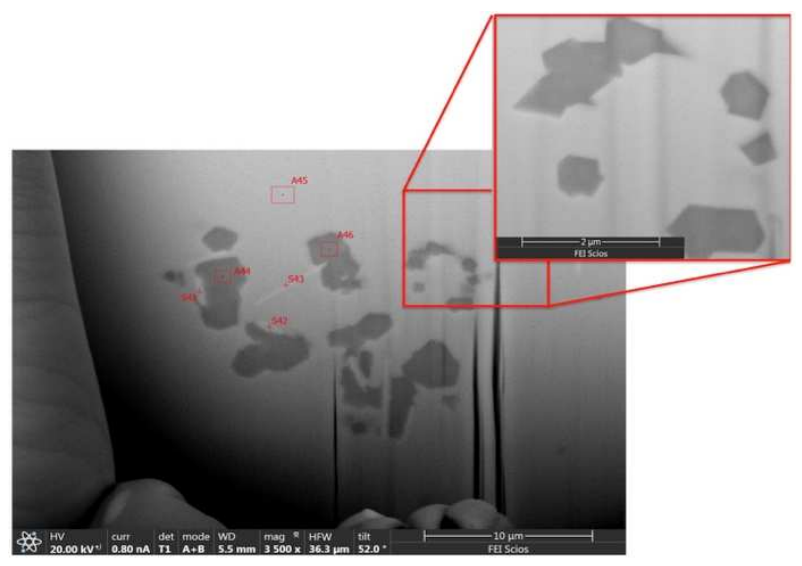

Fig. 7. Details of shear induced crystalline-phase grains

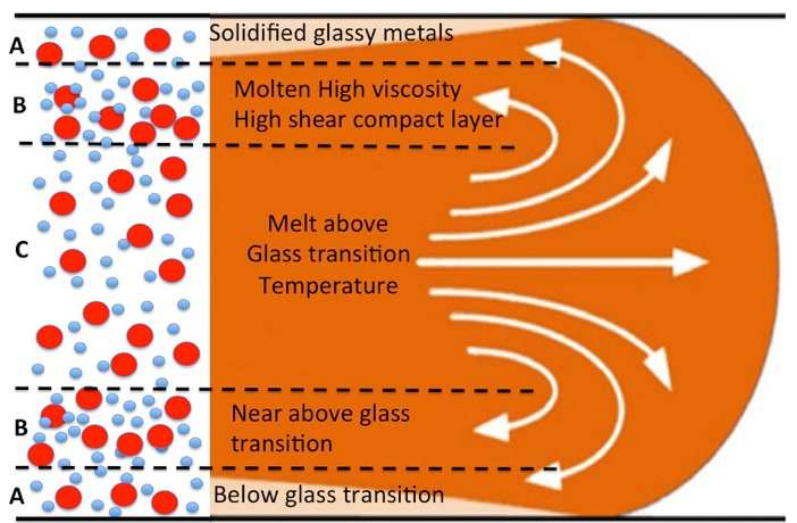

Fig. 8. High Shear stress build up in fountain flow front for injection molding of a $\mathrm{BMG}$

Table 1. Compositional EDS analyses of amorphous metal alloy glass and crystalline inclusions

\begin{tabular}{lllll}
\hline Atoms & $\begin{array}{l}\text { Amorphous } \\
\text { Surface }\end{array}$ & $\begin{array}{l}\text { Amorphous } \\
\text { Internal }\end{array}$ & $\begin{array}{l}\text { Hexagonal } \\
\text { Crystals }\end{array}$ & $\begin{array}{l}\text { Needle } \\
\text { Crystals }\end{array}$ \\
\hline $\mathrm{Zr}$ & $51,3 \pm 2,4$ & $43,8 \pm 2,5$ & $36,8 \pm 2,4$ & $47,2 \pm 2,5$ \\
$\mathrm{Ti}$ & $17,8 \pm 3,8$ & $18,6 \pm 4,7$ & $12,1 \pm 5,6$ & $14,8 \pm 5,4$ \\
$\mathrm{Ni}$ & $15,9 \pm 5,0$ & $18,3 \pm 6,8$ & $24,9 \pm 5,4$ & $19,1 \pm 7,2$ \\
$\mathrm{Cu}$ & $15,0 \pm 5,8$ & $18,8 \pm 8,1$ & $26,1 \pm 6,0$ & $17,1 \pm 8,0$ \\
\hline
\end{tabular}

Other sampling has been taken in other amorphous part such internal and external surfaces of the slab.

The comparative compositional analysis is reported in Table 1.

The composition of the amorphous glass metal is richer in $\mathrm{Zr}$ atoms $(51,3 \%)$ at the external surface (where the melt alloy is cooled at the fastest rate) while it is reduced in the internal layers $(43,8 \%$ at $20-60$ microns deep) where, conversely, the $\mathrm{Ni}$ and $\mathrm{Cu}$ atoms increase their composition from about 15 to $18 \%$ ).

The two types of crystalline inclusions are characterized by significantly different compositions.

The hexagonal crystals are composed by a $\mathrm{Ni}-\mathrm{Cu}$ rich phase (about $25 \%$ each) with $37 \%$ of $\mathrm{Zr}$ and $12 \%$ of $\mathrm{Ti}$. 
The needle crystals contain higher content of $\mathrm{Zr}$ compared to the needle crystal (47 Vs. 37\%) with $\mathrm{Cu}$ and $\mathrm{Ni}$ at $18 \%$ and $\mathrm{Ti}$ at $15 \%$.

These compositional differences could be attributed to the thermal and rheological behavior of the melt during the processing by injection molding.

These shear stresses, as it occurs for local crystallization in shear bands formed in highly deformed BMG's (Kanugo et al., 2004), considerably reduce the energy barriers for nucleation favoring the formation of nano and micro-crystalline phases.

In our samples sub-micron size crystal grains are observed in the layer between 20 and 40 microns from the external surface.

In this interfacial layer (B in Fig. 8) two driving forces are acting to induce crystal nucleation, the greater temperature difference from the thermodynamic melting temperature (the interlayer near above the glass transition) and the shorter distance between the crystallizing atoms (intense shear stresses squeeze and compact alloy atoms in a reduced volume, layer B in Fig. 8) favor crystal nucleation and growth.

Following the Potential Energy Landscape theory (Debenedetti and Stillinger, 2001; Klement et al., 1960), inherent structures, which are associated to energy local minima, are the equilibrium stable glassy states that are divided by energy barriers between the different potential equilibrium configurations.

This equilibrium glassy inherent structures may, under high shear and compressive conditions, become more compacted (layer B in Fig. 8) enhancing atomic redistribution in more ordered clusters prone to crystallization (the elastic compression energy is then stored in the crystalline phase).

According to a thermodynamic approach, the energy barrier $\left(\Delta \mathrm{G}^{*}\right)$ to overcome for a homogeneous nucleation from amorphous to crystalline phase is (Lee et al., 2006):

$$
\Delta G^{*}=\frac{16}{3} \pi \gamma^{3}\left(\frac{V_{m}^{c}}{\Delta G_{m}+E_{c}+P \Delta V_{m}}\right)
$$

Where

$T \quad=$ The temperature

$P \quad=$ The hydrostatic pressure

$\Delta G_{m}=$ The is the molar free energy change in the transformation between the amorphous and crystalline phases

$\gamma=$ The interfacial free energy between the amorphous and crystalline states (to form the critical size crystal nucleus)

$\Delta V_{m}=$ The molar volume change in the transformation between the amorphous $\left(V_{m}^{a}\right)$ and crystalline $\left(V_{m}^{c}\right)$ states, finally
$E_{c} \quad=$ The elastic strain energy induced by the change in volume in the crystallization process (with $E_{c}=\frac{1}{2} E \varepsilon^{2} V_{m}^{c} E_{c}$; with $\mathrm{E}$ the elastic modulus and $\varepsilon=\left(V_{m}^{a}-V_{m}^{c}\right) / 3 V_{m}^{c}$

According to the previous thermodynamic analysis, the presence of shear stresses increases the compaction of the atoms producing molar volume decreases leading to the reduction of the barrier energy $\Delta G^{*}$.

Equally, the near above temperature of the melt increase the value of the free energy $\Delta G_{m}$ lowering the energy barrier for crystallization.

\section{Conclusion}

The investigations of our research group on new materials and technologies in involving deep understanding of matter and their properties (Aversa et al., 2016a; 2016b; 2016c; 2016d; 2016e; 2016f; 2016g, 2016h; 2016i; 2016j; 2016k; 2016l; Petrescu et al., 2015; 2016).

The microscopic examination of internal sections of $\mathrm{Zr}_{44} \mathrm{Ti}_{11} \mathrm{Cu}_{10} \mathrm{Ni}_{10} \mathrm{Be}_{25}$ (LM001B), showed that the sample, also being characterized by an amorphous structure, has also a short-range order and crystalline clusters with a size range between 0.8 and $10 \mu \mathrm{m}$ can be detected.

Presence, behavior and distribution of crystalline phases for BMG basically can depend on oxygen impurity, microalloying elements and manufacturing process parameters.

Critical amount for quaternary and ternary $\mathrm{Zr}$ alloys is $0,4 \%$ (Murty and Hono, 2001). The size range of icosahedral phase is from 10 to $40 \mathrm{~nm}$ depending on the alloy.

Since Glass Forming Ability (GFA) can be defined also as the resistance to the precipitation of crystalline phases, oxygen has also a harmful effect on it (Eckert et al., 1998; Gebert et al., 1998), determining a lower processability of BMG.

Finally, as proven by microscopic observation, manufacturing process parameters, geometry, size and thickness have a significant effect on the formation of crystalline particles, on their quantity and their distribution. In fact, for more complex part and for manufacturing processes with a lower control of parameters, changes in cooling rate within the part occur, causing different behaviors of crystallization. Where the cooling rate is lower it is easier to find crystalline particles, especially in the interlayers between the solidified external glass metal and the still fluid, but near to its glass transition, highly shear strained melt.

\section{Acknowledgement}

The Authors acknowledge Liquid Metals Technologies Inc, Ca USA that kindly supply the samples for the characterization. 


\section{Author's Contributions}

All the Authors equally contributed to the experimental part and to the paper preparation.

\section{Ethics}

This article is original. Author declares that are not ethical issues that may arise after the publication of this manuscript.

\section{References}

Aversa, R. and A. Apicella, 2016. Factors affecting chemo-physical and rheological behaviour of $\mathrm{Zr}_{44^{-}}$ $\mathrm{Ti}_{11}-\mathrm{Cu}_{10}-\mathrm{Ni}_{10}-\mathrm{Be}_{25}$ metal glassy alloy supercooled liquids. Am. J. Eng. Applied Sci., 9: 98-106.

Aversa, R., F. Tamburrino, D. Parcesepe and A. Apicella, 2015. Cold crystallization behaviour of a commercial $\mathrm{Zr}_{44}-\mathrm{Ti}_{11}-\mathrm{Cu}_{10}-\mathrm{Ni}_{10}-\mathrm{Be}_{25}$ metal glassy Alloy. Adv. Mater. Res., 1088: 206-212. DOI: $10.4028 /$ www.scientific.net/AMR.1088.20

Aversa, R., F.I.T. Petrescu, R.V.V. Petrescu and A. Apicella, 2016a. Biofidel FEA modeling of customized hybrid biological hip joint design Part II: Flexible stem trabecular prostheses. Am. J. Biochem. Biotechnol.

Aversa, R., F.I.T. Petrescu, R.V.V. Petrescu and A. Apicella, 2016b. Biofidel FEA modeling of customized hybrid biological hip joint prostheses, Part I: Biomechanical behavior of implanted femur. Am. J. Biochem. Biotechnol.

Aversa, R., R.V.V. Petrescu, A. Apicella and F.I.T. Petrescu, 2016c. About Homeopathy or «Similia Similibus Curentur $\gg$. Am. J. Eng. Applied Sci.

Aversa, R., R.V. Petrescu, A. Apicella and F.I.T. Petrescu, 2016d. One can slow down the aging through antioxidants. Am. J. Eng. Applied Sci.

Aversa, R., E. Buzea, R.V.V. Petrescu, A. Apicella and M. Neacsa et al., 2016e. Present a mechatronic system having able to determine the concentration of carotenoids. Am. J. Eng. Applied Sci.

Aversa, R., R.V. Petrescu, R. Sorrentino, F.I.T. Petrescu and A. Apicella, 2016f. Hybrid ceramo-polymeric nanocomposite for biomimetic scaffolds design and preparation. Am. J. Eng. Applied Sci.

Aversa, R., V. Perrotta, R.V.V. Petrescu, C. Misiano and F.I.T. Petrescu et al., 2016g. From structural colors to super-hydrophobicity and achromatic transparent protective coatings: Ion plating plasma assisted $\mathrm{TiO}_{2}$ and $\mathrm{SiO}_{2}$ nano-film deposition. Am. J. Eng. Applied Sci.

Aversa, R., R.V. Petrescu, F.I.T. Petrescu and A. Apicella, 2016h. Biomimetic and evolutionary design driven innovation in sustainable products development. Am. J. Eng. Applied Sci.
Aversa, R., R.V.V. Petrescu, A. Antonio and F.I.T. Petrescu, 2016i. Mitochondria are naturally micro robots-A review. Am. J. Eng. Applied Sci.

Aversa, R., R.V.V. Petrescu, A. Apicella and F.I.T. Petrescu, 2016j. We are addicted to vitamins $\mathrm{C}$ and E-A review. Am. J. Eng. Applied Sci.

Aversa, R., R.V.V. Petrescu, A. Antonio and F.I.T. Petrescu, 2016k. Physiologic human fluids and swelling behavior of hydrophilic biocompatible hybrid ceramo-polymeric materials. Am. J. Eng. Applied Sci.

Aversa, R., R.V.V. Petrescu, A. Apicella and F.I.T. Petrescu, 20161. The basic elements of life's. Am. J. Eng. Applied Sci.

Bush, R., 2000. The thermophysical properties of bulk metallic glass-forming liquids. JOM, 52: 39-42. DOI: $10.1007 / \mathrm{s} 11837-000-0160-7$

Debenedetti, P.G. and F.H. Stillinger, 2001. Review article Supercooled liquids and the glass transition. Nature, 410: 259-267. DOI: 10.1038/35065704

Geyer, U., W.L. Johnson, S. Schneider, Y. Qiu and T.A. Tombrello et al., 1996. Small atom diffusion and breakdown of the Stokes-Einstein relation in the supercooled liquid state of the $\mathrm{Zr}_{46.7} \mathrm{Ti}_{8.3} \mathrm{Cu}_{7.5} \mathrm{Ni}_{10} \mathrm{Be}_{27.5}$ alloy. Phys. Rev. Lett., 75: 2492-2494.

Huang, Y., P. Xue, S. Guo, Y. Wu and X. Cheng et al., 2016. Liquid-solid joining of bulk metallic glasses. Sci. Rep., 29: 30674-30674. PMID: 27471073

Jamaluddin, S., N. Sahar, R. Aversa, R.V.V. Petrescu and D. Apicella et al., 2016. Periodontal bone substitutes application techniques and cost evaluation: A review. Am. J. Eng. Applied Sci.

Klement, W., R.H. Willens and P. Duwez, 1960. Noncrystalline structure in solidified gold-silicon alloys. Nature, 187: 869-870. DOI: 10.1038/187869b0

Kanugo, B.P., S.C. Gladeb, P. Asoka-Kumarb and K.M. Floresa, 2004. Characterization of free volume changes associated with shear band formation in $\mathrm{Zr}$ and $\mathrm{Cu}$-based bulk metallic glasses. Intermetallics, 12: 1073-1080. DOI: 10.1016/j.intermet.2004.04.033

Lee, S.W., M.Y. Huh, E. Feury and J.C. Lee, 2006. Crystallization-induced plasticity of $\mathrm{Cu}-\mathrm{Zr}$ containing bulk amorphous alloys. Acta Mater., 54: 349-355. DOI: 10.1016/j.actamat.2005.09.007

Lewandowski, J.J., W.H. Wang and A.L. Greer, 2005. Intrinsic plasticity or brittleness of metallic glasses. Philos. Mag. Lett., 85: 77-87. DOI: $10.1080 / 09500830500080474$

Liu, C.T., M.F. Chisholm and M.K. Miller, 2002. Oxygen impurity and microalloying effect in a $\mathrm{Zr}$ based bulk metallic glass alloy. Intermetallics, 10: 1105-1112. DOI: 10.1016/S0966-9795(02)00131-0

Morito, N. and T. Egami, 1984. Internal friction and reversible structural relaxation in the metallic glass $\mathrm{Fe}_{32} \mathrm{Ni}_{36} \mathrm{Cr}_{14} \mathrm{P}_{12} \mathrm{~B}_{6}$. Acta Metall., 32: 603-613. DOI: 10.1016/0001-6160(84)90071-3 
Murty, B.S. and K. Hono, 2001. Nanoquasicrystallization of Zr-based metallic glasses. Mater. Sci. Eng., 312: 253-261. DOI: 10.1016/S0921-5093(00)01861-X

Petrescu, R.V.V. R. Aversa, A. Apicella and F.I.T. Petrescu, 2016. Future medicine services robotics. Am. J. Eng. Applied Sci.

Petrescu, F.I.T., E. Buzea, L. Nănuţ, M. Neacşa and C. Nan, 2015. The role of antioxidants in slowing aging of skin in a human. Anal. Craiova Univ., 20: 567-574.

Trachenko, K., 2008. The Vogel-Fulcher-Tammann law in the elastic theory of glass transition. J. NonCrystalline Solids, 354: 3903-3906.

DOI: 10.1016/j.jnoncrysol.2008.05.021

Eckert, J., N. Mattern, M. Zinkevitch and M. Seidel, 1998. Crystallization behavior and phase formation in $\mathrm{Zr}-\mathrm{Al}-\mathrm{Cu}-\mathrm{Ni}$ metallic glass containing oxygen. Mater. Trans. JIM, 39: 623-632.

DOI: $10.2320 /$ matertrans 1989.39 .623
Gebert, A., J. Eckert and L. Schultz, 1998. Effect of oxygen on phase formation and thermal stability of slowly cooled $\mathrm{Zr}_{65} \mathrm{Al}_{7.5} \mathrm{Cu}_{7.5} \mathrm{Ni}_{10}$ metallic glass. Acta Mater., 46: 5475-5482. DOI: 10.1016/S1359-6454(98)00187-6

Pilarczyk, W. and J. Podworny, 2015. Study of atoms arrangment in zr-based bulk metallic glass structure. Acta Phys. Polonica A, 129: 216-218. DOI: 10.12693/APhysPolA.129.216

Saida, J., M. Matsushita and A. Inoue, 2000. Precipitation of an icosahedral quasicrystal phase in $\mathrm{Zr}_{70} \mathrm{Pd}_{20} \mathrm{Ni}_{10}$ amorphous alloy. Mater Trans. JIM, 41: 543-546. DOI: 10.2320/matertrans 1989.41.543 